Check for updates

Cite this: Phys. Chem. Chem. Phys., 2022, 24, 5138

Received 18th October 2021, Accepted 21st December 2021

DOI: $10.1039 / \mathrm{d} 1 \mathrm{cp} 04755 \mathrm{~h}$

rsc.li/pccp

\title{
Phenanthrene: establishing lower and upper bounds to the binding energy of a very weakly bound anion $\dagger$
}

\author{
Elisabeth Gruber, (D) $\ddagger^{\mathrm{a}}$ Siegfried Kollotzek, $\ddagger^{\mathrm{a}}$ Stefan Bergmeister, (D) ${ }^{\mathrm{a}}$ \\ Fabio Zappa, (D) Milan Ončák, (DD *a Paul Scheier (D) *a and Olof Echt (D)*ab
}

\begin{abstract}
Quite a few molecules do not form stable anions that survive the time needed for their detection; their electron affinities (EA) are either very small or negative. How does one measure the EA if the anion cannot be observed? Or, at least, can one establish lower and upper bounds to their EA? We propose two approaches that provide lower and upper bounds. We choose the phenanthrene (Ph) molecule whose EA is controversial. Through competition between helium evaporation and electron detachment in $\mathrm{He}_{n} \mathrm{Ph}^{-}$clusters, formed in helium nanodroplets, we estimate the lower bound of the vertical detachment energy (VDE) of $\mathrm{Ph}^{-}$as about $-3 \mathrm{meV}$. In the second step, $\mathrm{Ph}$ is complexed with calcium whose electron affinity is just $24.55 \mathrm{meV}$. When $\mathrm{CaPh}^{-}$ions are collided with a thermal gas of argon, one observes $\mathrm{Ca}^{-}$product ions but no $\mathrm{Ph}^{-}$, suggesting that the $\mathrm{EA}$ of $\mathrm{Ph}$ is below that of $\mathrm{Ca}$.
\end{abstract}

\section{Introduction}

The electron affinities (EAs) of molecules are of interest not only when negative ions are encountered in the gas phase but also in condensed-matter chemistry; electron-transfer reactions play a role in organic, biological, and catalytic processes. ${ }^{1}$ However, many molecules have vanishingly small adiabatic electron affinities; several common molecules such as $\mathrm{N}_{2}, \mathrm{H}_{2} \mathrm{O}$ or $\mathrm{CO}_{2}$ do not form stable anions at all. ${ }^{2}$ It is difficult to measure the EA of a molecule $\mathrm{M}$ that does not strongly bind an electron. A compilation of EAs determined by the photothreshold or photoelectron spectroscopy approach ${ }^{2}$ lists a total of 1101 atoms or molecules; only 13 of those have an EA below $100 \mathrm{meV}$, another 11 have an EA below $300 \mathrm{meV}$. If $\mathrm{M}$ does not form a longlived anion, how does one measure its EA?

In many cases, the lifetime of a weakly bound anion $\mathrm{M}^{-}$is too short for its observation because of thermally activated

\footnotetext{
${ }^{a}$ Institut für Ionenphysik und Angewandte Physik Universität Innsbruck Technikerstraße 25, 6020 Innsbruck, Austria. E-mail: Milan.Oncak@uibk.ac.at, Paul.Scheier@uibk.ac.at

${ }^{b}$ Department of Physics University of New Hampshire Durham, NH 03824, USA. E-mail:olof.echt@unh.edu

$\dagger$ Electronic supplementary information (ESI) available: Mass spectra including products from collision-induced dissociation. Computed electron affinities, vertical detachment energies, binding energies for phenanthrene complexed with one or more $\mathrm{He}, \mathrm{H}_{2}, \mathrm{H}_{2} \mathrm{O}$, and $\mathrm{Ph}$. Zero point energies for neutral and anionic $\mathrm{Ph}$ and $\mathrm{HePh}$. Cartesian coordinates of optimized structures. See DOI: 10.1039/ d1cp04755h

\# Both authors contributed equally.
}

electron emission. An obvious remedy is to lower the temperature. In the extreme case, one may try to form the anion within a liquid helium nanodroplet (HND) whose temperature is $0.37 \mathrm{~K}^{3}$ Excess helium may then be removed by collisions with a helium gas, until the bare $\mathbf{M}^{-}$emerges. ${ }^{4}$ But what if it doesn't? There is another trick that the experimenter has in her toolbox, namely complexing $\mathrm{M}^{-}$with a ligand $\mathrm{X}$. For example, clusters of $\mathrm{CO}_{2}$ or $\mathrm{H}_{2} \mathrm{O}$ form stable anions where the excess electron is bound due to long-range correlations with the electrons or, in the case of polar molecules, in the dipole field. ${ }^{2,5-11}$ The EA of a water cluster as small as the dimer equals $43 \mathrm{meV}$ even though the water monomer does not bind an electron. ${ }^{12}$

We demonstrate the viability of this two-pronged approach (synthesizing anions $\mathrm{XM}^{-}$in liquid HNDs) by studying complexes of phenanthrene $\left(\mathrm{Ph}, \mathrm{C}_{14} \mathrm{H}_{10}\right)$ with various ligands whose electron affinity is negative $\left(\mathrm{He}, \mathrm{H}_{2}, \mathrm{H}_{2} \mathrm{O}\right)$. With the exception of work by Lee et $a l .{ }^{13,14}$ which will be discussed further below, $\mathrm{Ph}^{-}$has so far escaped detection. ${ }^{15-18}$ Contradictory results have been reported for its electron affinity, namely $\approx 300 \mathrm{meV},{ }^{19-21} 120 \mathrm{meV},{ }^{13}$ and $-10 \pm 40 \mathrm{meV} .{ }^{18}$ The large $(300 \mathrm{meV})$ values were obtained by the electron capture detection method whose reliability has been questioned; ${ }^{18,22-24}$ the $120 \mathrm{meV}$ and $-10 \mathrm{meV}$ values are based on photoelectron (PE) measurements. ${ }^{13,18} \mathrm{~A}$ benchmark theoretical study of various polycyclic aromatic hydrocarbons places the EA of $\mathrm{Ph}$ at $-80 \mathrm{meV} .^{24}$ Several other theoretical studies agree that the EA is either very small, or negative. ${ }^{18,25}$

In the present work anions are formed by attaching electrons to helium nanodroplets (HNDs) which are subsequently passed through a pickup cell filled with a low-density vapor 
of phenanthrene, leading to large $\mathrm{He}_{n} \mathrm{Ph}^{-}$. Excess helium is then gently stripped from the doped, charged HNDs by multiple collisions with low-density helium gas until the emerging anions contain just a few helium atoms. Remarkably, we observe $\mathrm{He}_{n} \mathrm{Ph}^{-}, n>0$, but no bare $\mathrm{Ph}^{-}$. The same is true if massselected $\mathrm{He}_{n} \mathrm{Ph}^{-}, \mathrm{He}_{n} \mathrm{H}_{2} \mathrm{Ph}^{-}$or other small anionic complexes are collided with argon atoms. All possible anionic fragments of the precursor anion are detected, but bare $\mathrm{Ph}^{-}$is not.

A density functional theory (DFT) study of various neutral and negatively charged complexes of $\mathrm{Ph}$ shows that helium increases the EA by just a few meV. If such a small increase is sufficient to drastically increase the lifetime of the anion, then its EA must be very small.

A more accurate upper bound to the EA is obtained by synthesizing $\mathrm{He}_{n} \mathrm{CaPh}^{-}$. The EA of $\mathrm{Ca}$ is just $24.55 \mathrm{meV}^{26}$ Upon collision with argon atoms, $\mathrm{He}_{n} \mathrm{CaPh}^{-}$will shed its helium atoms and, eventually, dissociate into $\mathrm{Ca}^{-}+\mathrm{Ph}$ rather than into $\mathrm{Ca}+\mathrm{Ph}^{-}$. We conclude that the $\mathrm{EA}$ of $\mathrm{Ph}$ is less than $24.55 \mathrm{meV}$. Our approach is a variant of the well-established technique to bracket electron affinities by charge exchange reactions. If thermal collisions between $\mathbf{M}^{-}$and $\mathrm{X}$ produce predominantly $\mathrm{M}+\mathrm{X}^{-}$then the EA of $\mathrm{X}$ is larger than that of $\mathrm{M}$, because the branching ratio between two competing reaction channels in an activated system changes exponentially with the difference in the activation energies. ${ }^{27}$ The groups of Kebarle, Brauman, and Cooks, to name just a few, have made extensive use of this kinetic method to bracket EAs. ${ }^{20,28-30}$ Instead of studying the charge-exchange reaction (or its absence) between $\mathrm{Ca}^{-}$and $\mathrm{Ph}$, we study the half-reaction of $\mathrm{CaPh}^{-}$.

\section{Experimental details}

Neutral HNDs are grown by supersonic expansion of helium through a nozzle (diameter $5 \mu \mathrm{m}$, temperature $8 \mathrm{~K}$, stagnation pressure 25 bar) into ultra-high vacuum. The expanding beam is skimmed and ionized by electron attachment (energy $25 \mathrm{eV}$, current $330 \mu \mathrm{A}$ ). The resulting anions are weakly accelerated into an electrostatic hemispherical deflector set to transmit HNDs with a size-to-charge ratio $N / z \approx 3.5 \times 10^{6}$, below the critical size for doubly charged HND anions. ${ }^{31}$ The charged HNDs pass through a pickup cell into which phenanthrene (Sigma Aldrich, 99.5\%) is vaporized from an external oven kept at $50{ }^{\circ} \mathrm{C}$, and an "evaporation cell" that contains helium at low, variable pressure $P_{\text {evap. }}$. Multiple collisions will lead to partial or complete evaporation of helium from the doped HND. The helium pressure is tuned until negatively charged complexes of $\mathrm{Ph}$ and He emerge that contain just a few helium atoms. The ions are guided by a radio-frequency field into the extraction region of a time-of-flight mass spectrometer (TOFMS) equipped with a reflectron in V-configuration. The products of collision-induced dissociation of mass-selected ions are determined by first passing the ions that emerge from the evaporation cell through a quadrupole mass filter and then through a cell filled with argon gas at ambient temperature.

Negatively charged complexes containing $\mathrm{Ph}$ and $\mathrm{Ca}$ are formed by evaporating $\mathrm{Ca}$ and $\mathrm{Ph}$ in two separate pickup cells.
Other ligands $\left(\mathrm{H}_{2} \mathrm{O}, \mathrm{H}_{2}\right)$ result from collisions of the HNDs with residual gas, or ion-molecule reactions. Further details are described elsewhere. , $^{32,33}$

\section{Computational details}

There is a vast body of theoretical work that has been done to estimate the stability of very weakly bound, or even unbound, negative anions..$^{2,18,22-25,34,35}$ We have performed quantum chemical calculations of various Ph complexes using DFT along with the D3 dispersion correction as suggested by Grimme et al. ${ }^{36}$ Our calculations cannot asses electron affinities quantitatively, among other factors due to their high sensitivity to the zero-point energy correction as already discussed elsewhere. ${ }^{18}$ However, results obtained using the $\omega$ B97XD functional seem to be in reasonable agreement with available experiments. For example, calculated vertical detachment energies (VDE) of $\left(\mathrm{H}_{2} \mathrm{O}\right)_{n} \mathrm{Ph}^{-}, n=1-3$, are overestimated on average by 65 and $170 \mathrm{meV}$ at the $\omega \mathrm{B} 97 \mathrm{XD} / \mathrm{aug}-\mathrm{cc}-\mathrm{pVDZ}$ and B3LYP-D3/aug-ccpVDZ levels, respectively, compared to the experiment, ${ }^{18}$ see the ESI $\dagger$ (Fig. S6). The VDE of $\mathrm{Ph}_{2}{ }^{-}$is calculated as 249 and $527 \mathrm{meV}$ at the same levels of theory, the experimental value being $270 \mathrm{meV} .^{13}$ All used DFT functionals predict similar shifts in electron affinities of $\mathrm{Ph}$ when complexed with $\mathrm{He}, \mathrm{H}_{2}$ and $\mathrm{H}_{2} \mathrm{O}$. Only $\omega$ B97XD and B3LYP-D3 results are discussed below; benchmarking calculations can be found in the ESI $\dagger$ (Tables S1 and S2). Electron affinities include the zero-point correction, vertical detachment energies do not. Note that due to the system size, the zero-point correction is calculated within the harmonic approximation, which might lead to inaccuracies especially for neutral systems with attached helium atoms. Cluster structures were optimized using very tight convergence criteria; wave function stability was tested prior to every calculation. Complexes with more than one adsorbed atom or molecule are included in Fig. S5 and S6 (ESI $\dagger)$. All calculations were performed in the Gaussian software package. ${ }^{37}$

\section{Results and discussion}

A mass spectrum of HNDs doped with Ph is displayed in Fig. 1. Three distinct homologous ion series appear in Fig. 1a: $\mathrm{He}_{n} \mathrm{Ph}^{-}, \mathrm{He}_{n} \mathrm{H}_{2} \mathrm{Ph}^{-}$, and $\mathrm{He}_{n} \mathrm{H}_{2} \mathrm{OPh}^{-}$. Mass peaks due to ions that contain the main isotopes of each element $\left({ }^{1} \mathrm{H},{ }^{4} \mathrm{He},{ }^{12} \mathrm{C}\right.$, and ${ }^{16} \mathrm{O}$ ) are marked by symbols; connecting lines are drawn to guide the eye. The first member of each series (i.e. ions containing no helium, $n=0$ ) is labeled. ${ }^{38}$

The presence of ions containing a water impurity is unavoidable when working with very large HNDs. Tschurl et al. have reported PE spectra of $\left(\mathrm{H}_{2} \mathrm{O}\right)_{n} \mathrm{Ph}^{-}(n=1,2,3, n>0)$; the ions were prepared by seeding an expanding nitrogen gas with phenanthrene and water. ${ }^{18}$ They obtained a VDE of $270 \pm 20 \mathrm{meV}$ for $\mathrm{H}_{2} \mathrm{OPh}^{-}$; bare $\mathrm{Ph}^{-}$could not be observed.

Two features in Fig. 1a are striking: The presence of $\mathrm{HePh}^{-}$ and $\mathrm{H}_{2} \mathrm{Ph}^{-}$, and the absence of $\mathrm{Ph}^{-}$which cannot be positively identified; its yield is less than $3 \%$ relative to that of $\mathrm{HePh}^{-}$, 


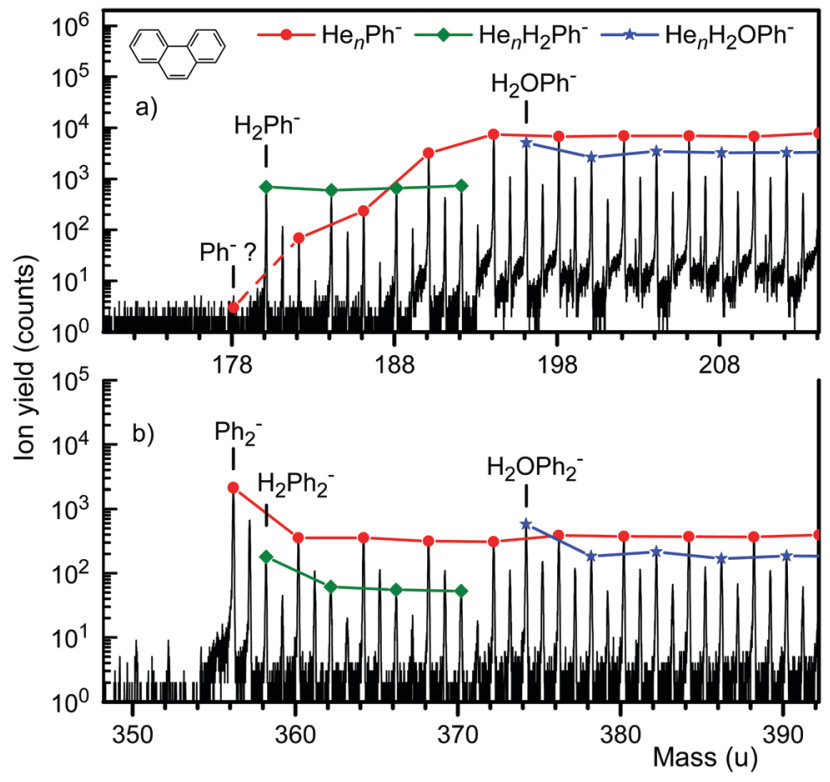

Fig. 1 Two sections of a negative ion mass spectrum of helium nanodroplets (HND) doped with phenanthrene $\left(\mathrm{Ph}, \mathrm{C}_{14} \mathrm{H}_{10}\right)$. Anionic complexes of $\mathrm{Ph}$ with $n>0$ helium atoms, or with $\mathrm{H}_{2}$ or $\mathrm{H}_{2} \mathrm{O}$ plus $n \geq 0$ helium atoms are observed in panel a, but bare $\mathrm{Ph}^{-}$is noticeably absent. Panel b shows the equivalent mass range for ions containing two $\mathrm{Ph}$ molecules. $\mathrm{Ph}_{2}{ }^{-}$ forms a prominent mass peak.

and less than $0.3 \%$ relative to $\mathrm{H}_{2} \mathrm{Ph}^{-}$. $\mathrm{HePh}^{-}$and $\mathrm{H}_{2} \mathrm{Ph}^{-}$are very weakly bound (see below). The temperatures of the observed anions $\mathrm{HePh}^{-}$and $\mathrm{H}_{2} \mathrm{Ph}^{-}$must be correspondingly low, ${ }^{39}$ hence the absence of $\mathrm{Ph}^{-}$suggests that the excess electron is very weakly bound.

Fig. 1b displays another section of the mass spectrum, revealing the same homologous ion series as in panel a but involving $\mathrm{Ph}_{2}$ rather than $\mathrm{Ph}$. Bare $\mathrm{Ph}_{2}{ }^{-}$forms a strong mass peak. Homologous ion series based on $\mathrm{Ph}_{3}{ }^{-}$(see the ESI $\dagger$ ) and larger $\mathrm{Ph}_{m}{ }^{-}$cluster ions are seen as well. The observation of intense $\mathrm{Ph}_{m}{ }^{-}$signals for $m>1$ agrees with previous work by Lee et al. who formed $\mathrm{Ph}_{m}{ }^{-}$by expansion of $\mathrm{Ph}$ vapor seeded in argon gas; free electrons were attached to $\mathrm{Ph}$ clusters in the expansion region. ${ }^{13,14}$

The ions that appear in Fig. 1 result from multiple collisions of large, doped, negatively charged HNDs with helium atoms at thermal energies. Each collision will transfer, on average, $0.05 \mathrm{eV}$ to the HND, about 80 times the evaporation energy of bulk helium. The spectrum does not convey any information about the immediate precursors of the observed ions or, turned around, the dissociation channels of a given ion. This information can be garnered from collision-induced-dissociation (CID) spectra, which were recorded by passing the ions that emerge from the evaporation cell through a quadrupole mass filter. The selected precursor ions are accelerated and sent into a cell where they collide with a thermal gas of argon; product ions are then analyzed in the TOFMS. ${ }^{32,33,40}$

Two CID spectra are presented in Fig. 2. The relative yield of $\mathrm{He}_{n} \mathrm{Ph}^{-}$fragments from the precursor ion $\mathrm{He}_{4} \mathrm{Ph}^{-}$(panel a) decreases rapidly from $2.5 \%$ for $\mathrm{He}_{3} \mathrm{Ph}^{-}$to $0.09 \%$ for $\mathrm{HePh}^{-}$.

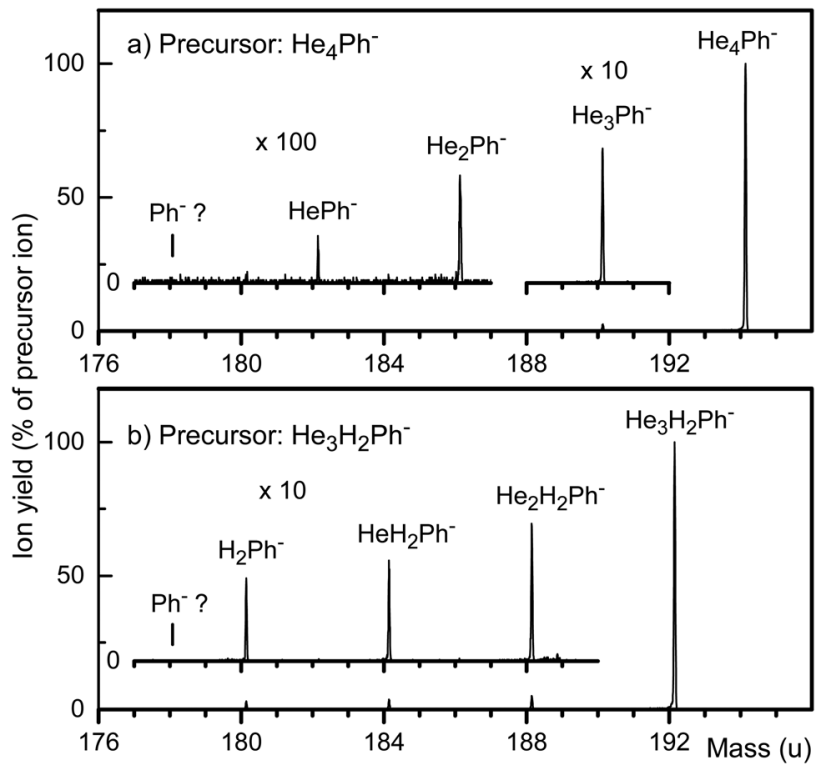

Fig. 2 Mass spectra of ions produced by collisions of precursor ions $\mathrm{He}_{4} \mathrm{Ph}^{-}$and $\mathrm{He}_{3} \mathrm{H}_{2} \mathrm{Ph}^{-}$(panels $\mathrm{a}$ and $\mathrm{b}$, respectively) with argon atoms at $2 \mathrm{eV}$ ion energy (in the lab system) and an argon gas pressure of $0.8 \mathrm{mPa}$. Various fragment ions are observed, but no bare $\mathrm{Ph}^{-}$

$\mathrm{Ph}^{-}$cannot be identified; its relative yield is less than $0.005 \%$ of the precursor, or $5 \%$ of $\mathrm{HePh}^{-}$. Thus, when $\mathrm{He}_{4} \mathrm{Ph}^{-}$is excited by collisions, it may shed one, two or three atoms without losing its electron, ${ }^{41}$ but the electron will detach upon loss of the fourth and last helium atom.

Fig. 2b displays a CID spectrum of $\mathrm{He}_{3} \mathrm{H}_{2} \mathrm{Ph}^{-}$. The relative yield of product ions due to loss of one, two, or three He equals a few percent but no bare $\mathrm{Ph}^{-}$is detected. Its relative yield is less than $0.002 \%$ of the precursor, or $0.06 \%$ of $\mathrm{H}_{2} \mathrm{Ph}^{-}$. The preference for He loss rather than $\mathrm{H}_{2}$ loss is not surprising, given that the polarizability of $\mathrm{H}_{2}$ is nearly four times larger than that of He.

The data in Fig. 2a and b reveal a striking difference between the ion series $\mathrm{He}_{n} \mathrm{Ph}^{-}$and $\mathrm{He}_{n} \mathrm{H}_{2} \mathrm{Ph}^{-}$; the yield of the former increases rapidly with size $n$ while that of the latter remains constant. The same trends are apparent in the mass spectrum in Fig. 1a (note the logarithmic scale). We tentatively attribute the rapid increase of the $\mathrm{He}_{n} \mathrm{Ph}^{-}$yield to its very low stability for small values of $n$. Even a slight increase in its stability with increasing $n$, as discussed further below, will then greatly extend its lifetime. $\mathrm{He}_{n} \mathrm{H}_{2} \mathrm{Ph}^{-}$, on the other hand, is already quite stable even if $n=0$.

The CID spectra of $\left(\mathrm{H}_{2} \mathrm{O}\right)_{n} \mathrm{Ph}^{-}$and $\mathrm{Ph}_{m}{ }^{-}$are presented in the ESI. $\dagger$ These anions shed their ligands $\left(\mathrm{H}_{2} \mathrm{O}\right.$ and $\mathrm{Ph}$, respectively) upon collision-induced dissociation, but bare $\mathrm{Ph}^{-}$is not produced. To summarize, any of the ligands explored so far $\left(\mathrm{He}, \mathrm{H}_{2}, \mathrm{H}_{2} \mathrm{O}, \mathrm{Ph}\right)$ will stabilize $\mathrm{Ph}^{-}$, but the EA of bare $\mathrm{Ph}$ is too small (or perhaps even negative) for the detection of its anion.

Calculated complexes of $\mathrm{Ph}$ with $\mathrm{He}, \mathrm{H}_{2}, \mathrm{H}_{2} \mathrm{O}$ and $\mathrm{Ph}$ are shown in Fig. 3, along with binding energies, vertical detachment energies and electron affinities. The binding energies of $\mathrm{HePh}$ and $\mathrm{HePh}^{-}$were evaluated as 7.3 and $10.0 \mathrm{meV}$, respectively, at the 
a)
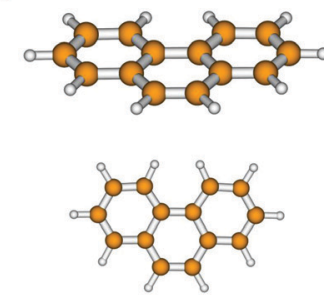

Ph

$E A=41(190)$

b)

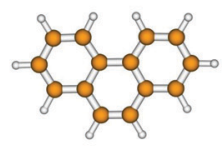

$\mathrm{Ph}^{-}$

VDE $=78(180)$
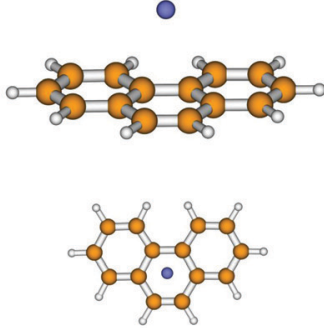

HePh

$E A=43$ (191)

$E_{\text {bind }}=7.3(8.8)$

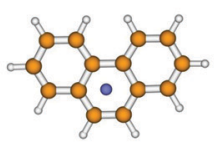

$\mathrm{HePh}^{-}$

$\mathrm{VDE}=80$ (182)

$E_{\text {bind }}=10.0(10.1)$
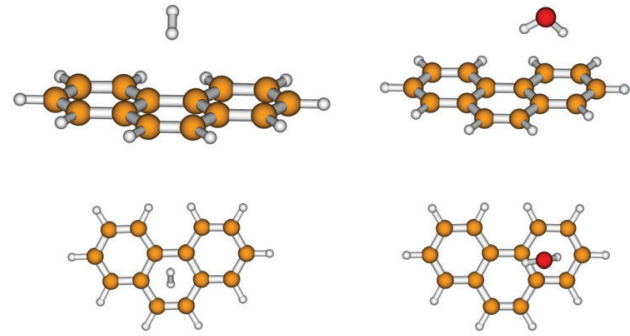

$\mathrm{H}_{2} \mathrm{Ph}$

$\mathrm{EA}=70(211)$

$E_{\text {bind }}=28.0$ (41.9)

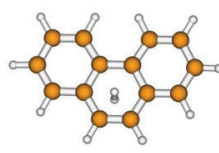

$\mathrm{H}_{2} \mathrm{Ph}^{-}$

VDE $=110(216)$

$E_{\text {bind }}=57.8(62.9)$

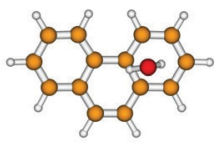

$\mathrm{H}_{2} \mathrm{OPh}$

$E A=281$ (430)

$E_{\text {bind }}=151(156)$

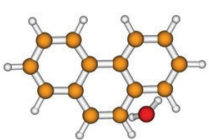

$\mathrm{H}_{2} \mathrm{OPh}^{-}$

VDE $=377$ (482)

$E_{\text {bind }}=392(397)$
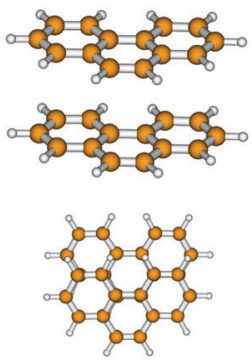

$\mathrm{Ph}_{2}$

$E A=74$ (474)

$E_{\text {bind, }}=605$ (466)

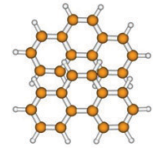

$\mathrm{Ph}_{2}$

VDE $=249$ (527)

$E_{\text {bind }}=638(750)$

Fig. 3 Structures of $\mathrm{Ph}, \mathrm{HePh}, \mathrm{H}_{2} \mathrm{Ph}, \mathrm{H}_{2} \mathrm{OPh}$ and $\mathrm{Ph}_{2}$ shown in side and top views (a) and their anionic counterparts shown in top view (b) along with adiabatic electron affinities (EA), vertical detachment energies (VDE) and binding energies $\left(E_{\text {bind }}\right)$, all in meV. Energies are given as calculated at the $\omega B 97 X D / a u g-c c-p V D Z$ level; B3LYP-D3/aug-cc-pVDZ results are shown in parenthesis. Structures optimized at the B3LYP-D3/aug-cc-pVDZ level are displayed. Note that the VDE values are not zero-point corrected, leading to VDE $<$ EA for Ph and HePh. The considerable difference in EA(Ph $\left.{ }_{2}\right)$ for the two functionals can be traced to different structures of $\mathrm{Ph}_{2}{ }^{-}$, see Fig. $\mathrm{S} 7$ (ESl $\dagger$ ).

$\omega \mathrm{B} 97 \mathrm{XD} /$ aug-cc-pVDZ level (Fig. 3). The stronger interaction with He in the anion compared to the neutral molecule leads to an increased electron affinity of $\mathrm{HePh}$ compared to $\mathrm{Ph}$; the difference, however, is of the order of meV. For $\mathrm{He}_{n} \mathrm{Ph}^{-}, n=1-3$, our calculations show that each helium atom increases both electron affinity and vertical detachment energy by about 1-3 meV (Fig. S5, $\mathrm{ESI} \dagger$ ), in agreement with the trend observed in the experiment.

Calculations on $\mathrm{HePh}^{-}$give us the possibility to estimate the lower bound of the phenanthrene electron affinity. As the $\mathrm{HePh}^{-}$ion is observed in the experiment, $\mathrm{VDE}\left(\mathrm{HePh}^{-}\right)$should be $>0 \mathrm{meV}$. The computed VDE of $\mathrm{Ph}^{-}$is $2-3 \mathrm{meV}$ lower than that of $\mathrm{HePh}^{-}$, hence $\operatorname{VDE}\left(\mathrm{Ph}^{-}\right)>\approx-3 \mathrm{meV}$. On the other hand, the upper bound of the VDE should not be much higher than several meV as the $\mathrm{Ph}^{-}$ion itself is not observed in the mass spectrum. The electron affinity must be lower than the VDE; if zero-point effects are neglected, the difference between EA and VDE in phenanthrene is calculated as 191 (150) meV employing the $\omega$ B97XD (B3LYP) functional, in reasonable agreement with a previous calculation of $153 \mathrm{meV},{ }^{18}$ see Table S3 (ESI $\dagger)$. This suggests that the $\mathrm{He}_{n} \mathrm{Ph}^{-}$ions observed in the experiment are metastable for small $n$, and the method could be used for preparing metastable anionic species for further spectroscopic studies.

Similarly, complexation of $\mathrm{Ph}$ with $\mathrm{H}_{2}, \mathrm{H}_{2} \mathrm{O}$ and Ph leads to an increase in electron affinity due to a stronger interaction in the anionic molecule compared to the neutral one. In $\left(\mathrm{H}_{2}\right)_{n} \mathrm{Ph}^{-}$ and $\left(\mathrm{H}_{2} \mathrm{O}\right)_{n} \mathrm{Ph}^{-}$complexes, each $\mathrm{H}_{2}$ and $\mathrm{H}_{2} \mathrm{O}$ increases the electron affinity by about 15 to 30 and 190 to $240 \mathrm{meV}$, respectively, for $n=1-3$ (see Fig. S5 and S6, ESI $\dagger$ ). Finally, the vertical detachment energy of $\mathrm{Ph}_{2}{ }^{-}$was calculated to lie about 200-350 meV above that of $\mathrm{Ph}$ (Fig. 3), rationalizing observation of this ion in the experiment.
We can also establish an experimental upper bound of the electron affinity by investigating negatively charged complexes of $\mathrm{Ph}$ with $\mathrm{Ca}$. The EA of $\mathrm{Ca}, 24.55 \mathrm{meV}$, is smaller than that of any other atom that forms a stable anion. ${ }^{26} \mathrm{If}_{\mathrm{CaPh}}{ }^{-}$is mildly excited in low-energy collisions, what are the products?

The main isotope of $\mathrm{Ca}$ is ${ }^{40} \mathrm{Ca}$ (mass $39.963 \mathrm{u}$, abundance 96.941\%). When $\mathrm{Ph}$ and $\mathrm{Ca}$ are co-vaporized in the pickup cell, the mass peak at nominally $218 \mathrm{u}$ in the negative ion mass spectrum contains contributions from ${ }^{40} \mathrm{CaPh}^{-}$, but $\mathrm{H}_{2} \mathrm{O}^{40} \mathrm{Ca}_{5}{ }^{-}$ and $\mathrm{He}_{10} \mathrm{Ph}^{-}$contribute as well. Their mass peaks are resolved in the TOF spectrum but the quadrupole mass filter that selects ions for the CID measurements cannot separate those precursor ions. Sections of a CID spectrum of mass 218 ions are displayed in Fig. 4; complete spectra are presented in the ESI. $\dagger{ }^{40} \mathrm{Ca}^{-}$ forms, by far, the most prominent product ion peak; its relative yield increases from $0.03 \%$ to $0.3 \%$ as the pressure of the argon collision gas is raised from $0.8 \mathrm{mPa}$ to $4 \mathrm{mPa}$ (panels a and $\mathrm{b}$, respectively). A much weaker signal appears at $178 \mathrm{u}$ which, however, is due to $\mathrm{Ca}$ loss from $\mathrm{H}_{2} \mathrm{OCa}_{5}{ }^{-}$rather than $\mathrm{Ca}$ loss from $\mathrm{CaPh}^{-}$. Once again, $\mathrm{Ph}^{-}$cannot be positively identified.

The full CID mass spectrum of mass 218 ions (see ESI $\dagger$ ) reveals a few other mass peaks that are due to $\mathrm{He}$ loss from $\mathrm{He}_{10} \mathrm{Ph}^{-}$or loss of one or more $\mathrm{Ca}$ atoms from $\mathrm{H}_{2} \mathrm{OCa}_{5}{ }^{-}$. A critical reader might argue that $\mathrm{Ca}^{-}$product ions originate from $\mathrm{H}_{2} \mathrm{OCa}_{5}{ }^{-}$rather than from $\mathrm{CaPh}^{-}$. This is, however, easily ruled out by turning off the $\mathrm{Ph}$ source: As shown in the ESI, $\dagger$ the $\mathrm{Ca}^{-}$signal disappears to $<0.0001 \%$ of the precursor ion while ions due to loss of $\mathrm{H}_{2} \mathrm{O}, \mathrm{H}_{2}$, and one or two $\mathrm{Ca}$ atoms from $\mathrm{H}_{2} \mathrm{OCa}_{5}{ }^{-}$persist at a few $\%$.

So far, we have not considered another possible reaction channel, namely electron detachment. Our setup is blind to this channel; we cannot detect neutral products nor free electrons. Competition between electron detachment and dissociation 


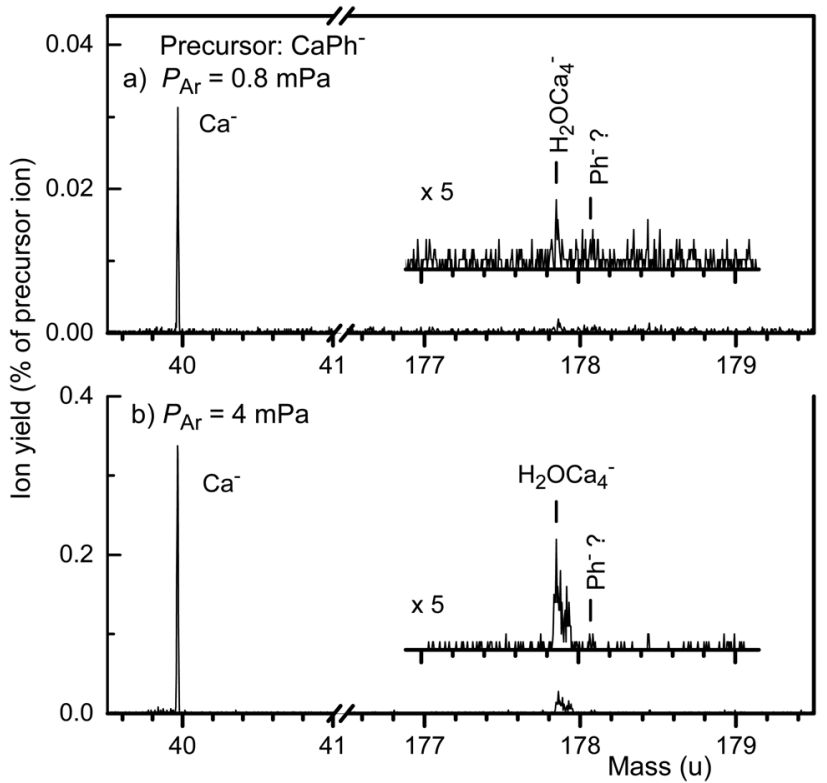

Fig. 4 Mass spectra of ions produced by collisions of $\mathrm{CaPh}^{-}$with argon atoms at $5 \mathrm{eV}$ ion energy (in the lab system) at two different argon pressures (panels a and $\mathrm{b}$ ). The main product ion is $\mathrm{Ca}^{-}$. A contamination of the parent ion mass peak at $218 \mathrm{u}$ by $\mathrm{H}_{2} \mathrm{OCa}_{5}{ }^{-}$gives rise to $\mathrm{H}_{2} \mathrm{OCa}_{4}{ }^{-}$ product ions. $\mathrm{Ph}^{-}$is not positively identified.

occurs, for example, for $\left(\mathrm{H}_{2} \mathrm{O}\right)_{n}{ }^{-8}$. The relative yield of the competing channels does not only depend on the activation energies but also on the excess energy available. ${ }^{42}$ Still, electron detachment would merely reduce the anion yield; it would not affect the competition between formation of $\mathrm{Ca}^{-}$and $\mathrm{Ph}^{-}$.

Hence the main result is that $\mathrm{Ca}^{-}$is the only fragment ion produced by collisional excitation of $\mathrm{CaPh}^{-}$. No $\mathrm{Ph}^{-}$ions are detected. We conclude that the $\mathrm{EA}$ of $\mathrm{Ph}$ is well below that of $\mathrm{Ca}$ (24.55 meV), and certainly not much larger. The conclusion is consistent with PE data by Tschurl et al. ${ }^{18}$ but at variance with PE data by Lee $e t a l^{13,14}$ Lee $e t$ al. observed prominent mass peaks due to $\mathrm{Ph}_{m}{ }^{-}$ions, $m>1$, and a very weak mass peak near $178 \mathrm{u}$ that they assigned to bare $\mathrm{Ph}^{-}$. They deduced a VDE of $120 \mathrm{meV}$ from a PE spectrum of these ions. Their stated mass resolution, however, was just $1 / 200$; the full width of mass peaks in their published data measures about $2.5 \mathrm{u}$. It is conceivable that the true mass of the observed anions differed slightly from $178 \mathrm{u}$. They used a primary electron beam of $400 \mathrm{eV}$; secondary electrons were assumed to attach to $\mathrm{Ph}$ to produce $\mathrm{Ph}^{-}$. $\mathrm{Ph}$ has a strong resonance at $7.7 \mathrm{eV}$ for dissociative attachment to produce $(\mathrm{Ph}-\mathrm{H})^{-} \cdot{ }^{17}$ Alternatively, the PE spectrum reported by Lee et al. might be due to $\mathrm{H}_{2} \mathrm{Ph}^{-}$which contributes strongly to the negative ion mass spectrum as seen in Fig. 1. Its PE spectrum would probably resemble that of $\mathrm{Ph}_{m}{ }^{-}, m>1$, except for a spectral blue shift. On the other hand, the measured blueshift ${ }^{13,14}$ is significantly larger than the one predicted by our calculations.

\section{Conclusion}

To summarize, we have shown that long-lived $\mathrm{He}_{n} \mathrm{Ph}^{-}$anions can be formed in HNDs and fragmented by low-energy collisions with Ar into $\mathrm{He}_{x} \mathrm{Ph}^{-}$as small as $x=1$. However, bare $\mathrm{Ph}^{-}$cannot be observed although calculations show that a single helium atom increases the EA of Ph by just a few meV. If an increase in the EA by a few $\mathrm{meV}$ stabilizes the anion, its EA as well as its temperature must be very low. More quantitatively, we observe that $\mathrm{HePh}^{-}$is stable while $\mathrm{Ph}^{-}$is not, enabling us to estimate the lower bound of $\operatorname{VDE}\left(\mathrm{Ph}^{-}\right)$as $\approx-3 \mathrm{meV}$. At the same time, collisions of $\mathrm{CaPh}^{-}$produce $\mathrm{Ca}^{-}$but no $\mathrm{Ph}^{-}$, indicating that the $\mathrm{EA}$ of $\mathrm{Ph}$ is below that of $\mathrm{Ca}$, i.e. below $24.55 \mathrm{meV}$. This work shows that very weakly bound, previously unobservable anions can be formed in HNDs; it outlines a method to determine bounds to their VDE and EA, and proposes $\operatorname{VDE}(\mathrm{Ph})>-3 \mathrm{meV}$ and $\mathrm{EA}(\mathrm{Ph})<24.55 \mathrm{meV}$.

\section{Conflicts of interest}

The authors declare no conflict of interest.

\section{Acknowledgements}

We thank E. Illenberger for providing improved copies of the Figures in ref. 17 The work by S. B., E. G. O. E., and S. K. was supported by the FWF, Projects W1259, T1181, P31149, and I4130. The computational results have been achieved using the HPC infrastructure LEO of the University of Innsbruck.

\section{References}

1 P. Kebarle and S. Chowdhury, Chem. Rev., 1987, 87, 513-534.

2 J. C. Rienstra-Kiracofe, G. S. Tschumper, H. F. Schaefer, S. Nandi and G. B. Ellison, Chem. Rev., 2002, 102, 231-282.

3 A. Mauracher, O. Echt, A. M. Ellis, S. Yang, D. K. Bohme, J. Postler, A. Kaiser, S. Denifl and P. Scheier, Phys. Rep., 2018, 751, 1-90.

4 P. Martini, M. Goulart, L. Kranabetter, N. Gitzl, B. Rasul, P. Scheier and O. Echt, J. Phys. Chem. A, 2019, 123, 4599-4608.

5 V. G. Bezchastnov, V. P. Vysotskiy and L. S. Cederbaum, Phys. Rev. Lett., 2011, 107, 133401.

6 S. M. Ciborowski, G. Liu, J. D. Graham, A. M. Buytendyk and K. H. Bowen, Eur. Phys. J. D, 2018, 72, 139.

7 M. Knapp, O. Echt, D. Kreisle, T. D. Märk and E. Recknagel, Chem. Phys. Lett., 1986, 126, 225-231.

8 M. Knapp, O. Echt, D. Kreisle and E. Recknagel, J. Phys. Chem., 1987, 91, 2601-2607.

9 J. R. Roscioli, N. I. Hammer and M. A. Johnson, J. Phys. Chem. A, 2006, 110, 7517-7520.

10 V. P. Vysotskiy, L. S. Cederbaum, T. Sommerfeld, V. K. Voora and K. D. Jordan, J. Chem. Theory Comput., 2012, 8, 893-900.

11 J. M. Weber, E. Leber, M. W. Ruf and H. Hotop, Eur. Phys. J. $D, 1999,7,587-594$.

12 J. V. Coe, S. T. Arnold, J. G. Eaton, G. H. Lee and K. H. Bowen, J. Chem. Phys., 2006, 125, 014315.

13 S. H. Lee, N. Kim, D. G. Ha and J. K. Song, $R S C A d v .$, 2013, 3, 17143-17149. 
14 S. H. Lee, J. K. Song and S. K. Kim, Chem. Phys. Lett., 2015, 626, 63-68.

15 M. v. Ardenne, K. Steinfelder and R. Tümmler, Angew. Chem., 1961, 73, 136-142.

16 R. V. Khatymov, R. F. Tuktarov and M. V. Muftakhov, JETP Lett., 2011, 93, 437-441.

17 S. Tobita, M. Meinke, E. Illenberger, L. G. Christophorou, H. Baumgärtel and S. Leach, Chem. Phys., 1992, 161, 501-508.

18 M. Tschurl, U. Boesl and S. Gilb, J. Chem. Phys., 2006, 125, 194310.

19 R. S. Becker and E. Chen, J. Chem. Phys., 1966, 45, 2403-2410.

20 G. D. Chen and R. G. Cooks, J. Mass Spectrom., 1995, 30, 1167-1173.

21 L. Wojnarovits and G. Foldiak, J. Chromatogr., 1981, 206, 511-519.

22 L. D. Betowski, M. Enlow and D. H. Aue, Int. J. Mass Spectrom., 2006, 255, 123-129.

23 L. D. Betowski, M. Enlow, L. Riddick and D. H. Aue, J. Phys. Chem. A, 2006, 110, 12927-12946.

24 M. Huzak, B. Hajgato and M. S. Deleuze, Chem. Phys., 2012, 406, 55-64.

25 G. Malloci, G. Mulas, G. Cappellini, V. Fiorentini and I. Porceddu, Astron. Astrophys., 2005, 432, 585-594.

26 T. Andersen, H. K. Haugen and H. Hotop, J. Phys. Chem. Ref. Data, 1999, 28, 1511-1533.

27 S. L. Craig, M. Zhong, B. Choo and J. I. Brauman, J. Phys. Chem. A, 1997, 101, 19-24.

28 P. Kebarle, Int. J. Mass Spectrom., 2000, 200, 313-330.

29 D. M. Wetzel and J. I. Brauman, Chem. Rev., 1987, 87, 607-622.

30 R. G. Cooks and P. S. H. Wong, Acc. Chem. Res., 1998, 31, 379-386.

31 F. Laimer, F. Zappa, P. Scheier and M. Gatchell, Chem. - Eur. J., 2021, 27, 7283-7287.

32 L. Tiefenthaler, J. Ameixa, P. Martini, S. Albertini, L. Ballauf, M. Zankl, M. Goulart, F. Laimer, K. von Haeften, F. Zappa and P. Scheier, Rev. Sci. Instrum., 2020, 91, 033315.
33 L. Tiefenthaler, S. Kollotzek, M. Gatchell, K. Hansen, P. Scheier and O. Echt, J. Chem. Phys., 2020, 153, 164305.

34 M. Puiatti, D. M. A. Vera and A. B. Pierini, Phys. Chem. Chem. Phys., 2009, 11, 9013-9024.

35 C. P. Vibert and D. J. Tozer, J. Chem. Theory Comput., 2019, 15, 241-248.

36 S. Grimme, J. Antony, S. Ehrlich and H. Krieg, J. Chem. Phys., 2010, 132, 154104.

37 M. J. Frisch, G. W. Trucks, H. B. Schlegel, G. E. Scuseria, M. A. Robb, J. R. Cheeseman, G. Scalmani, V. Barone, G. A. Petersson, H. Nakatsuji, X. Li, M. Caricato, A. V. Marenich, J. Bloino, B. G. Janesko, R. Gomperts, B. Mennucci, H. P. Hratchian, J. V. Ortiz, A. F. Izmaylov, J. L. Sonnenberg, D. Williams-Young, F. Ding, F. Lipparini, F. Egidi, J. Goings, B. Peng, A. Petrone, T. Henderson, D. Ranasinghe, V. G. Zakrzewski, J. Gao, N. Rega, G. Zheng, W. Liang, M. Hada, M. Ehara, K. Toyota, R. Fukuda, J. Hasegawa, M. Ishida, T. Nakajima, Y. Honda, O. Kitao, H. Nakai, T. Vreven, K. Throssell, J. A. Montgomery Jr., J. E. Peralta, F. Ogliaro, M. J. Bearpark, J. J. Heyd, E. N. Brothers, K. N. Kudin, V. N. Staroverov, T. A. Keith, R. Kobayashi, J. Normand, K. Raghavachari, A. P. Rendell, J. C. Burant, S. S. Iyengar, J. Tomasi, M. Cossi, J. M. Millam, M. Klene, C. Adamo, R. Cammi, J. W. Ochterski, R. L. Martin, K. Morokuma, O. Farkas, J. B. Foresman and D. J. Fox, Gaussian 16, Revision A.03, 2016.

38 Each of these mass peaks is followed by a satellite peak at $1 \mathrm{u}$ larger mass and a relative yield of $\approx 1 / 15$; these satellites are due to ions that contain one $13 \mathrm{C}$ atom.

39 C. E. Klots, Z. Phys. D, 1991, 20, 105-109.

40 L. Tiefenthaler, S. Kollotzek, A. M. Ellis, P. Scheier and O. Echt, Phys. Chem. Chem. Phys., 2020, 22, 28165-28172.

41 Products of collision-induced electron detachment would go undetected, but the observation of product anions clearly shows that not all collisions result in electron detachment.

42 L. A. Posey, P. J. Campagnola, M. A. Johnson, G. H. Lee, J. G. Eaton and K. H. Bowen, J. Chem. Phys., 1989, 91, 6536-6538. 